\title{
Using Kahoot! As A Formative Assessment Tool in Science Teacher Education
}

\author{
Noluthando Mdlalose ${ }^{1}$, Sam Ramaila ${ }^{1} \&$ Umesh Ramnarain $^{1}$ \\ ${ }^{1}$ Department of Science and Technology Education, Faculty of Education, University of Johannesburg, South Africa \\ Correspondence: Sam Ramaila, Department of Science and Technology Education, Faculty of Education, University \\ of Johannesburg, South Africa.
}

Received: July 19, 2021

Accepted: September 8, 2021

Online Published: September 9, 2021

doi:10.5430/ijhe.v11n2p43

URL: https://doi.org/10.5430/ijhe.v11n2p43

\begin{abstract}
The development of $21^{\text {st }}$ century competencies and skills in science teaching and learning is a key strategic imperative. Game-based learning platforms can be used to promote pedagogic innovation in various educational settings. Game-based applications such as Kahoot! have been increasingly used in education to facilitate meaningful enactment of formative assessment practices. Within the realm of science education, formative assessment is largely perceived as an assessment practice with pedagogic potential to enhance students' academic performance, motivation and engagement during the teaching and learning process. Kahoot! is an interactive game-based learning platform which can essentially be utilised to enhance students' academic performance, motivation and engagement in the classroom. This paper explores the role of Kahoot! as a formative assessment tool to enhance students' academic performance, motivation and engagement with a view to help students to achieve stipulated learning outcomes during remote teaching and learning in undergraduate Physical Sciences teacher education. The research study adopted a generic qualitative design and involved 21 purposively selected preservice Physical Sciences teachers at a South African university. Data was collected through semi-structured interviews and the administration of qualitative user-generated online quizzes with the participants. The findings demonstrated that Kahoot! plays a significant role in enhancing students' academic performance, motivation and active engagement during remote teaching and learning. Theoretical implications for technology-enhanced teaching and learning are discussed.
\end{abstract}

Keywords: formative assessment, Kahoot!, teacher education, remote teaching and learning

\section{Introduction}

South African universities transitioned to remote teaching and learning as a result of the prevalence of COVID-19 pandemic. The transition to remote teaching and learning involved the utilisation of various online tools and resources. The dominant online tools used by South African universities include Blackboard, learning management systems, Moodle and Coursera (Chaka, 2020). There is a need to adopt alternative online resources to augment online tools used by South African universities to foster meaningful teaching and learning in higher education in particular. As a game-based learning platform, Kahoot! is an example of an alternative innovative resource that can be harnessed to augment online tools being used within the broader South African context.

According to Stuart, Akyeampong and Croft (2009), assessment in teacher education should be created and administered to keep track of what student teachers learn and their progress towards achieving the program's outcomes. Assessment refers to a continuous and planned process of identifying and gathering information about the performance of students (Bansal, 2020). Identified, collected and analyzed students' performance information makes it possible to provide appropriate assistance to students and leads to the improvement and modification of teaching and learning (Tosuncuoglu, 2018). Formative assessment can be conducted at various stages in a particular program. Formative assessment is described as assessment for learning which is mainly used to inform students about their learning progress and how to improve their learning experience (Stuart et al., 2009). Ismail et al. (2019) argue that "formative assessment is most effective when it is embedded in the teaching and learning activities to facilitate the provision of ongoing, timely, specific and actionable feedback to students" (p.1). In addition, formative assessment can be administered using various technological platforms such as game-based learning platforms such as Kahoot!. As an innovative resource, Kahoot! is an emerging user-friendly game-based learning application that has been widely used in educational institutions. This interactive game-based learning platform can be used by teachers to create multiple-choice quizzes, surveys, polls questions, jumble and discussions through which students can engage and 
challenge one another with the top scorer or overall winner displayed on a scoreboard at the end of the game session (Ismail et al., 2019; Ismail \& Mohammad, 2017).

The integration and adaptation of interactive game-based applications in teaching and learning environments has gained momentum in recent years. By their very nature, game-based applications facilitate the enforcement of relevant technology-enhanced teaching approaches to improve students' overall learning experiences, engagement and motivation during the learning process (Chaiyo \& Nokham, 2017; Licorish, Owen, Daniel \& George, 2018; Omar, 2017). Modern students are proficient in the use of technologies and teachers are required to create learning environments which provide meaningful opportunities for students to experiment and enjoy learning through the use of various technological devices and game-based learning applications. Game-based learning has grown in popularity in the educational space by virtue of its effectiveness as compared to traditional methods of learning. Game based learning is an active learning technique which involves the use of games to enhance student learning. Various research studies conducted on game-based learning reported numerous benefits associated with the integration of game-based applications over traditional methods (Ismail et al., 2019). The reported benefits include significant improvement in student academic performance, enhancement of student learning experience, as well as enhancement of students' motivation and engagement. Furthermore, various research studies have also demonstrated that Kahoot! has the potential to enhance students' capability to successfully relate to lectures and lecture notes by putting more effort into revision of lectures, recalling important points and discovering new information in a fun way, improving students' retention power and providing immediate feedback to both teachers and students about their progress (Arif, Zubir, Mohamad \& Yunus, 2019; Nadeem \& Al Falig, 2020).

At another pragmatic level, the use of Kahoot! can help students to achieve the intended learning outcomes, enhance students' motivation and engagement while learning in a fun manner (Sabandar, Supit \& Suryana, 2018). In addition, Kahoot! can be used synchronously and asynchronously as a formative assessment tool depending on the nature of the teaching and learning environment. Within the context of this study, Kahoot! has been used synchronously and asynchronously as a formative assessment tool in Physical Sciences teacher education module during remote teaching and learning at a South African university. As the use of Kahoot! within the higher education sector in South Africa is still in its infancy, there is a critical need to explore its role as a formative assessment tool to enhance students' academic performance, engagement, and motivation with a view to help students to achieve stipulated learning outcomes particularly during remote teaching and learning.

\section{Theoretical Framework}

The study is underpinned by the Assessment for Formative Purposes Cycle proposed by Harlen (2006) as the underlying theoretical framework. The Assessment for Formative Purposes Cycle is illustrated in Figure 1 below. The framework itself places students in the center of the cycle as they are actively involved in the learning process. The cycle is initiated by a clear identification and understanding of the envisaged goals to be achieved at the end of the learning process, followed by the activities that students engage with in order to achieve stipulated learning goals. Finally, the results from student activities serve as evidence for learning and are analyzed and interpreted in order to identify possible gaps that learners might have and make decisions about the next steps on how to support the learners to ensure that they have meaningful learning experience to help them achieve stipulated learning goals. 


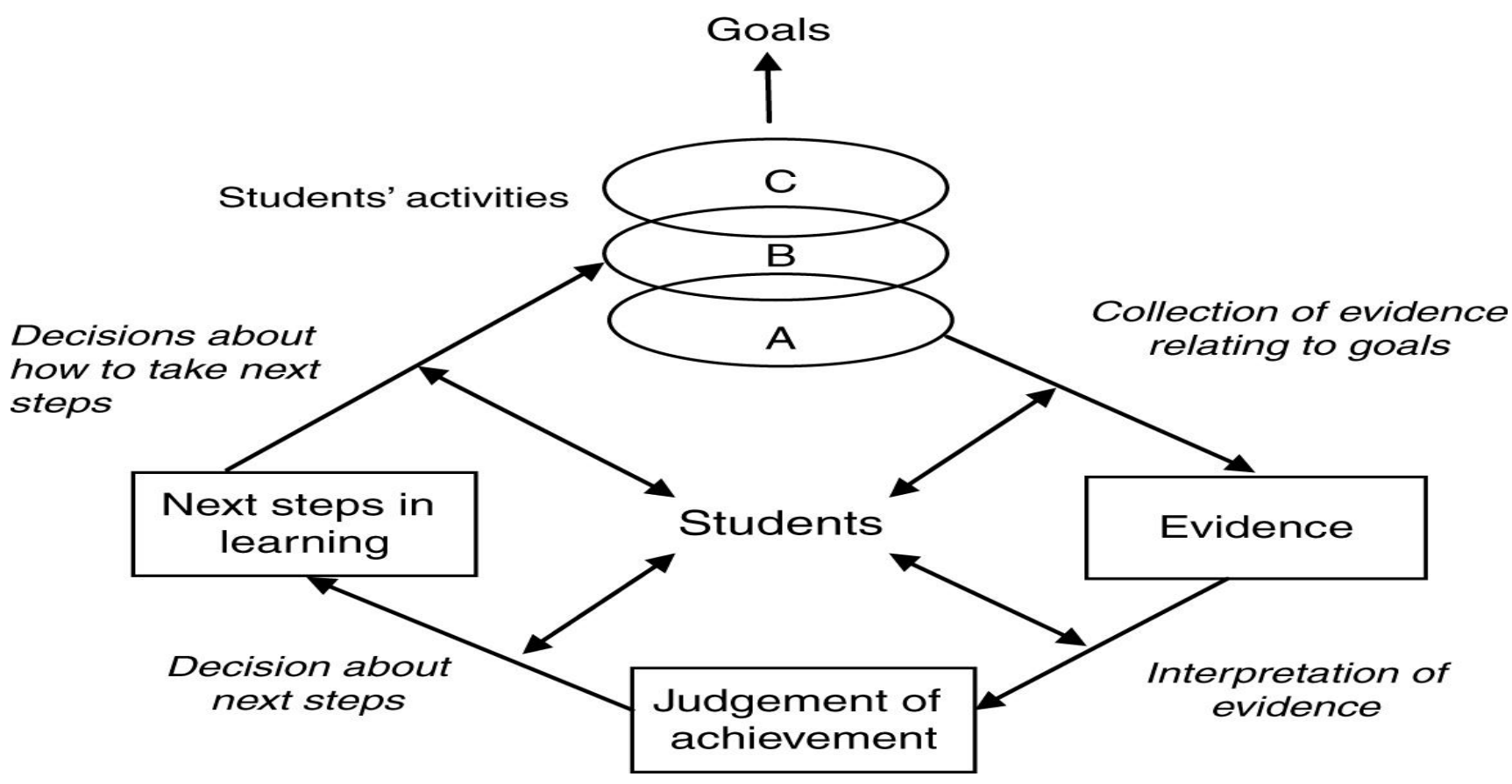

Figure 1. Assessment for Formative Purposes Cycle (Harlen, 2006)

\section{Purpose of the Study}

Within the realm of science education, formative assessment is largely perceived to be an assessment practice with pedagogic potential to enhance students' academic performance, motivation and engagement during the learning process. As an interactive game-based learning platform, Kahoot! is effective in enhancing students' academic achievement, motivation and engagement in the classroom (Licorish, Owen, Daniel, \& George, 2018). As postulated earlier, the use of Kahoot! within the higher education sector in South Africa is still in its infancy. This practical consideration underscores the need to explore the role of Kahoot! as a formative assessment tool to enhance students' academic performance, engagement, and motivation with a view to help students to achieve stipulated learning outcomes particularly during remote teaching and learning. This study examines the role of Kahoot! as a formative assessment tool in science teacher education. The empirical investigation is underpinned by the following concomitant objectives:

- To investigate the role of Kahoot! as a formative assessment tool to enhance students' academic performance, motivation, engagement with a view to help students to achieve stipulated learning outcomes during remote teaching and learning in undergraduate Physical Sciences teacher education.

- $\quad$ To explore students' experiences and perceptions about the use of Kahoot! during remote teaching and learning.

This study is guided by the following research questions:

- How can Kahoot! be used as a formative assessment tool to enhance students' academic performance, engagement and motivation during remote teaching and learning?

- To what extent does Kahoot! as a formative assessment tool help students to achieve stipulated learning outcomes during remote teaching and learning?

\section{Research Design and Methodology}

The study adopted a generic qualitative design and involved 21 purposively selected pre-service Physical Sciences teachers at a South African university. The demographic profile of the participants is provided in Table 1 below.

Table 1. Demographic profile of the participants

\begin{tabular}{lclcl}
\hline Gender & & Age & & Degree enrolled for \\
\hline Male & 9 & $18-25$ years & 17 & Bachelor of Education \\
Female & 12 & $25-30$ years & 4 & Bachelor of Education \\
\hline
\end{tabular}


The game-based learning platform (Kahoot!) was used as a part of a Bachelor of Education program in the second semester of 2020 (between July and November). More specifically, Kahoot! was used to administer quizzes on various topics to assess students' conceptual understanding. Data were collected through semi-structured interviews and administration of qualitative user-generated online quizzes (Kahoots!) with the participants. The qualitative user-generated online quizzes were administered to 21 preservice Physical Sciences teachers while semi-structured interviews were conducted with 5 selected participants after the administration of online quizzes. The participants' responses from online quizzes framed the questions posed during semi-structured interviews. Semi-structured interviews were conducted remotely through Blackboard discussion forums in line with Covid-19 regulations. Data was transcribed verbatim and categorized. Axial coding was used to analyse interview data while Kahoot! generated feedback provided insightful elucidation into pervasive knowledge gaps exhibited by the students. Common patterns were identified and emerging themes were generated from participants' narratives.

The trustworthiness of qualitative data was evaluated by using the criterion developed by Lincoln and Guba (1985). This criterion is characterized by four key components: credibility, transferability, dependability, and confirmability. Data analysis was conducted in a precise, consistent, and exhaustive manner through recording, systematizing, and disclosing the methods of analysis with enough detail in order to ensure credibility. An external researcher was afforded the opportunity to conduct external audit on the research study to ensure dependability. The research context and the assumptions that were central to the research were adequately described to enhance transferability. To ensure confirmability, the research process and interpretations of data were verified by an independent reviewer. According to Merriam (2009), the validity of the study can be ensured by conducting the investigation in an ethical manner. Validity refers to the extent to which a study measures what it intends to measure. In respect of qualitative data, the following validity and reliability checks recommended by Merriam (1998) were adhered to.

\section{a) Triangulation}

Triangulation refers to the investigation of a social phenomenon using more than one source of data (Bryman, 2008). In this study, various sources of data and data collection methods were used to confirm emerging findings.

\section{b) Member checks}

Data and tentative interpretations were individually checked by all researchers. Each researcher verified transcribed data and the verification process provided opportunities to check the accuracy of data to ensure that what is captured was a true reflection of the observed phenomenon.

\section{c) Peer review}

There was an ongoing dialogue and critical reflection with other researchers on the research process and tentative interpretations. This was important to reach consensus on various interpretations.

\section{Results}

Key findings emanating from the study are categorized according to three broad themes, namely: Use of Kahoot! for revision and reflection purposes, time as a key factor when administering online quizzes and synchronous and asynchronous administration of online quizzes.

\section{Theme 1: Use of Kahoot! for revision and reflection purposes}

The first research question, "How can Kahoot! be used as a formative assessment tool to enhance students' academic performance, engagement and motivation during remote teaching and learning?", sought to investigate the role of Kahoot! as a formative assessment tool to enhance students' academic performance, motivation, engagement with a view to help students to achieve stipulated learning outcomes during remote undergraduate Physical Sciences teaching and learning. The students indicated that online quizzes provided meaningful opportunities to revise content covered during the interactive discussion sessions. In addition, online quizzes facilitated diagnosis of knowledge gaps which subsequently informed deployment of appropriate remedial interventions. This sentiment is reflected in the following excerpt.

"The questions standards are very good and helped us to go over the content we have already covered and notice what we still need to work more on. I love the fact that the questions that a majority of students got wrong, the lecturer will revise that content and go over it again with the students. This is a very effective way of revision".

The students further indicated that the use of Kahoot! provides meaningful opportunities to reflect on their own learning. This sentiment is encapsulated in the following excerpt. 
"The use of Kahoot! enables us to identify problematic conceptual areas that require additional emphasis. Conceptual hurdles can then be collaboratively discussed to ensure meaningful conceptual understanding.The use of Kahoot! keeps us engaged in the lesson and affords us opportunities to critically reflect on the content presented".

\section{Theme 2: Time as a key factor when administering online quizzes}

Prior training on the use of Kahoot! was provided to the participants to ensure that they are able to use the platform properly. The students appeared to struggle with time management during the initial administration of online quizzes. This observation underscored the need to adjust time allocation per question in subsequent quizzes. The students' performance was inadequate in the first quiz administered and this can be attributed to their inability to manage allocated time when engaging with online quizzes. Time management appeared to be a significant operational challenge for the students in the initial stages of quiz administration as the following excerpt illustrates.

"While the time set for each question is reasonable, I had difficulty managing time to read through all the answers properly. In some instances, I had to guess answers as I ran out of time".

The students indicated that time management can be improved through sustained active involvement in the use of Kahoot! as a game-based learning platform. This sentiment is encapsulated in the following excerpt.

"Our time management can get better if additional opportunities are given to use Kahoot! as a learning tool. Learning can be enhanced with more practice on the use of Kahoot!".

Table 2 below provides students' overall performance in the first online quiz

Table 2. Students' overall performance in the first online quiz

\section{Overall Performance}

Total correct answers $(\%)$

$7,69 \%$

Total incorrect answers $(\%)$

Average score (points)
$92,31 \%$

194,15 points

Students' overall performance in the first quiz necessitated operational adjustments to be made. Time allocation was adjusted to allow students to read and understand each question. Implemented time allocation adjustments engendered improved students' overall performance in the second online quiz as reflected in Table 3 below.

Table 3. Students' overall performance in the second online quiz

\section{Overall Performance}

\begin{tabular}{ll|}
\hline Total correct answers $(\%)$ & $28,57 \%$ \\
\hline Total incorrect answers $(\%)$ & $71,43 \%$ \\
\hline Average score (points) & 1593,93 points \\
\hline
\end{tabular}

\section{Theme 3: Synchronous and asynchronous administration of online quizzes}

The user-generated online quizzes were firstly administered asynchronously in order to allow students to take the quiz at their own suitable time while giving due consideration to data costs. However, this provision limited the discussion process during the synchronous discussion sessions and students could not recall their responses for further elaboration. As a result, online quizzes were then administered synchronously during remote teaching and learning. The students actively participated in discussion sessions. The students further indicated that they were able to refer to their results and provide elaboration on their responses as the feedback was displayed on the screen in real time. This assertion is evidenced by the sentiment encapsulated in the following excerpt.

"The provision of synchronous feedback enabled us to critically reflect on our answers thereby stimulating learning of content presented"

Synchronous administration of online quizzes during remote teaching and learning served to develop students' understanding of content before moving to the next question. The critical feedback gleaned made it possible to identify and adequately address conceptual hurdles. The critical feedback was further harnessed to stimulate 
interactive discussions which were aimed at helping students to develop a meaningful understanding of content presented. The students expressed fundamental appreciation for synchronous administration of online quizzes as it compelled them to prepare for discussion sessions in advance. In addition, synchronous administration of online quizzes served to enhance students' engagement and motivation during discussion sessions. However, synchronous administration of online quizzes was in some instances adversely affected by bandwidth problems as the followings excerpt illustrates.

"The quiz task seemed to be fun and more engaging, sadly I could not play because my device was giving me problems and I had connectivity issues".

At another pragmatic level, the students indicated that asynchronous administration of online quizzes can sometimes lead to dishonesty as they could collaboratively complete online quizzes. This sentiment is captured in the following excerpt.

\section{"Asynchronous administration of Kahoot quizzes requires fidelity and commitment on our part as some students can take advantage of the situation".}

The second research question, "To what extent does Kahoot! as a formative assessment tool help students to achieve stipulated learning outcomes during remote teaching and learning?", sought to explore students' experiences and perceptions about the use of Kahoot! during remote undergraduate Physical Sciences teaching and learning. The students demonstrated a positive disposition about the use of Kahoot! as a means to achieve stipulated learning outcomes during remote teaching and learning. Students' overall performance in the third quiz reflected further improvement as illustrated in Table 4 below. This improvement can be attributed to students' increased confidence in the use of Kahoot!.

Table 4. Students' performance on their third quiz attempt

\begin{tabular}{|l|l|}
\hline Overall Performance & \\
\hline Total correct answers (\%) & $49,57 \%$ \\
\hline Total incorrect answers (\%) & $50,43 \%$ \\
\hline Average score (points) & 4039,74 points \\
\hline
\end{tabular}

The students indicated that the use of Kahoot! served to enhance their learning experiences through provision of additional opportunities. This assertion is corroborated by the following excerpt.

"The questions made us think as some of the answers were very close to each other so it was difficult to choose between them. You had to really think. It was very fun and informative. It was a very good exercise".

\section{Discussion}

Key findings emanating from this study demonstrated that Kahoot! plays a significant role in enhancing students' academic performance, motivation and engagement during remote teaching and learning. Sustained use of Kahoot! as a game-based learning platform appeared to enhance students' overall academic performance as evidenced by the results obtained in subsequent quizzes. In addition, the use of Kahoot! provided opportunities for students to actively engage and work collaboratively as a community of practice. Collaborative and interactive discussions were a source of motivation for students to learn. As a formative assessment tool, Kahoot! served to help students to achieve stipulated learning outcomes and provided valuable insights into pervasive knowledge gaps. It was further observed that when students were instructed to engage with online quizzes at their own time as homework, they sometimes forgot to take the online quizzes and their preparation was largely inadequate. The discrepancy between synchronous and asynchronous feedback underscores the need to provide opportunities for students to engage with online quizzes independently to ensure objective appraisal of their content knowledge. The use of Kahoot! as a game-based learning platform provided meaningful opportunities to adequately address pervasive knowledge gaps. The findings are consistent with a study conducted by Ismail et al., (2019) which found that the use of game-based learning platforms serves to enhance student learning experience, motivation and engagement. The use of Kahoot! enriches the quality of student learning in the classroom and significantly influences classroom dynamics, engagement, motivation and improved learning experience (Licorish, Owen, Daniel, \& George, 2018). Research studies conducted by Barrio et al. (2016) and Wang and Lieberoth (2016) demonstrated that educational games and game-based student response systems both increase student motivation and engagement. Holmes and Gee (2016) contend that although the 
gamification process is not new in education, the technologies that are supporting these interventions have been evolving from single use to collaborative and distributed contexts.

The synchronous administration of online quizzes promoted active interactions between the lecturer and students and facilitated provision of immediate feedback to students. These active interactions took the form of peer collaborative engagements which provided meaningful opportunities for the students to collaboratively reflect on content presented. Johns (2015) concurs with this notion by emphasizing that the learning activities which can be incorporated in Kahoot! must be designed in a manner that affords students opportunities to interact with their instructors and their peers and receive immediate meaningful feedback during teaching and learning sessions. Students' overall performance in the first online quiz revealed the existence of content knowledge gaps which required provision of additional opportunities to be addressed through deployment of appropriate remedial interventions.

Wang and Tahir (2020) posit that while students demonstrated a positive disposition about the use of Kahoot! as a learning tool, they bemoan challenges stifling their full engagement and participation such as technical challenges, difficulty in reading both questions and answers in the projected screen, time pressure, fear of losing and the difficulty in catching up when the wrong answer had been given. On the other hand, several researchers suggested that these challenges can create apprehension on the part of students which may have an adverse impact on students' enjoyment, motivation and concentration when undertaking the quiz (e.g., Chaiyo \& Nokham, 2017; Ismail \& Fakri, 2017; Tan \& Saucerman, 2017; Wang 2015; Wang \& Lieberoth, 2016). However, Ismail and Mohammad (2017) argue that students perceive Kahoot! as fun and effective platform providing immediate feedback and conclude that "Kahoot! is a promising formative assessment tool that is feasible, practical, fun, and enjoyable" (p.19). Jui-Mei et al. (2011) point out that the performance of students who learn using game-based learning platforms is better as compared to those who learn using traditional methods.

\section{Interpretation of key findings in terms of the adopted theoretical framework}

As indicated earlier, the study is underpinned by the Assessment for Formative Purposes Cycle proposed by Harlen (2006) as the underlying theoretical framework. In terms of framework, the learning goals were clearly stipulated and communicated to the students before engaging in Kahoot! activities. Students' overall performance in online quizzes and interview responses highlighted the existence of pervasive knowledge gaps which required provision of additional opportunities to address through coherent deployment of appropriate remedial interventions. Inadequate students' overall performance in the initial online quiz required professional judgment to be made on their achievement before proceeding to the next learning steps. The identification of factors that influenced the performance of students in the initial stages paved the way for putting appropriate measures in place to enhance subsequent students' overall performance. Professional judgement of students' achievement provided opportunities to critically reflect on appropriate adjustments to be implemented. The implementation of appropriate adjustments engendered improved students' overall performance in subsequent stages. Improved students' overall performance in subsequent stages implies that careful consideration ought to be given to the following aspects when using Kahoot! as a formative assessment tool in teaching and learning, namely: student activities, collection of evidence related to goals, interpretation of evidence, decisions about next steps, and decisions about how to take next steps.

\section{Conclusion}

The use of Kahoot! as a formative assessment tool during remote teaching and learning serves to enhance students' engagement and motivation. In addition, the use of Kahoot! provides opportunities to address pervasive knowledge gaps as evidenced by students' positive disposition about the effectiveness of Kahoot! as a game-based learning platform. Sustainable use of Kahoot! served to improve students' overall performance. In addition, the use of Kahoot! provided opportunities for students to actively engage and work collaboratively as a community of practice. There is a critical need to harness pedagogical affordances of game-based learning platforms such as Kahoot! to maximize students' academic experience in higher education with a view to ensure epistemic and epistemological access. In particular, game-based learning platforms can be utilized to demystify abstract scientific concepts. Harnessing pedagogical affordances of game-based learning platforms such as Kahoot! can serve as an innovative catalyst for fostering meaningful science teaching and learning within the broader South African context. 


\section{References}

Arif, F. K. M., Zubir, N. Z., Mohamad, M., \& Yunus, M. M. (2019). Benefits and challenges of using game-based formative assessment among undergraduate students. Humanities \& Social Sciences Reviews, 7(4), $203-213$. https://doi.org/10.18510/hssr.2019.7426

Bansal, G. (2020). Understanding gaps in teacher interpretation of formative assessment evidence. School Science Review, 101(377), 67-72.

Barrio, C. M., Muñoz-Organero, M., \& Soriano, J. S. (2016). Can gamification improve the benefits of student response systems in learning? An experimental study. IEEE Transactions on Emerging Topics in Computing, 4(3), 429-438. https://doi.org/10.1109/TETC.2015.2497459

Chaiyo, Y., \& Nokham, R. (2017, March). The effect of Kahoot, Quizizz and Google Forms on the student's perception in the classrooms response system. In 2017 International Conference on Digital Arts, Media and Technology (ICDAMT) (pp. 178-182). IEEE. https://doi.org/10.1109/ICDAMT.2017.7904957

Chaka, C. (2020). Higher education institutions and the use of online instruction and online tools and resources during the COVID-19 outbreak - An online review of selected U.S. and SA's universities. Research Square, 1-46. https://doi.org/10.21203/rs.3.rs-61482/v1

Johns, K. (2015). Engaging and assessing students with technology: A review of Kahoot!. Delta Kappa Gamma Bulletin, 81(4), 89-91.

Harlen, W. (2006). Teaching, Learning and Assessing Science 5 - 12. 4th edn. London: Sage.

Harlen, W. (2013). Assessment \& inquiry-based science education: Issues in policy and practice. Global Network of Science Academies.

Holmes, J. B., \& Gee, E. R. (2016). A framework for understanding game-based teaching and learning. On the Horizon, 24(1), 1-16. https://doi.org/10.1108/OTH-11-2015-0069

Ismail, M. A. A., Ahmad, A., Mohammad, A. M., Fakri, N. M. R. M., Nor, M. Z. M., \& Pa, M. J. M. (2019). Using Kahoot! as a formative assessment tool in medical education: a phenomenological study. BMC Medical Education, 19, 230. https://doi.org/10.1186/s12909-019-1658-z

Ismail, M. A. A., \& Mohammad, J. A. M. (2017). Kahoot: A promising tool for formative assessment in medical education. Education in Medicine Journal, 9(2), 230. https://doi.org/10.21315/eimj2017.9.2.2

Ismail, M. A. A., \& Fakri, N. M. R. M. (2017). Transforming stressful to joyful classroom through web 2.0 applications. In Carnival on e-learning (IUCEL) (pp. 199-201). Malaysia: Negeri Sembilan.

Licorish, S. A., Owen, H. E., Daniel, B., \& George, J. L. (2018). Students' perception of Kahoot!'s influence on teaching and learning. Research and Practice in Technology Enhanced Learning, 13(9), 1-23. https://doi.org/10.1186/s41039-018-0078-8

Lincoln, S. Y., \& Guba, E. G. (1985). Naturalistic inquiry. Thousand Oaks, CA: Sage. https://doi.org/10.1016/0147-1767(85)90062-8

Nadeem, N. H., \& Al Falig, H. A. (2020). Kahoot! Quizzes: A Formative Assessment Tool to Promote Students' Self-Regulated Learning Skills. Journal of Applied Linguistics and Language Research, 7(4), 1-20.

Omar, N. N. (2017). The Effectiveness of Kahoot application towards students' good feedback practice. International Journal of Social Sciences, 3(2), 2551-2562. https://doi.org/10.20319/pijss.2017.32.25512562

Sabandar, G., Supit, N., \& Suryana, E. (2018). Kahoot!: Bring the Fun Into the Classroom! Indonesian Journal of Informatics Education, 2(2), 127-134. https://doi.org/10.20961/ijie.v2i2.26244

Stuart, J., Akyeampong, K., \& Croft, A. (2009). Key Issues in Teacher Education: a sourcebook for teacher educators in developing countries. Macmillan.

Tan, P., \& Saucerman, J. (2017). Enhancing learning and engagement through gamification of student response systems. In ASEE annual conference \& exposition. https://doi.org/10.18260/1-2--28276

Tosuncuoglu, I. (2018). Importance of Assessment in ELT. Journal of Education and Training Studies, 6(9), 163-167. https://doi.org/10.11114/jets.v6i9.3443

Wang, A. I. (2015). The wear out effect of a game-based student response system. Computers \& Education, 82, 217-227. https://doi.org/10.1016/j.compedu.2014.11.004 
Wang, A. I., \& Lieberoth, A. (2016). The effect of points and audio on concentration, engagement, enjoyment, learning, motivation, and classroom dynamics using Kahoot!. In Proceedings from the 10th European Conference on Games Based Learning, (p. 738). Reading, UK: Academic Conferences International Limited.

Wang, A. I., \& Tahir, R. (2020). The effect of using Kahoot! for learning - A literature review. Computers \& Education, 149, 103818. https://doi.org/10.1016/j.compedu.2020.103818

Yien, J. M., Hung, C. M., Hwang, G. J., \& Lin, Y. C. (2011). A game-based learning approach to improving students' learning achievements in a Nutrition course. Turkish Online Journal of Educational Technology-TOJET, 10(2), 1-10.

\section{Copyrights}

Copyright for this article is retained by the author(s), with first publication rights granted to the journal.

This is an open-access article distributed under the terms and conditions of the Creative Commons Attribution license (http://creativecommons.org/licenses/by/4.0/). 